\title{
Cultural Globalization from the Perspective of Post-colonialism
}

\author{
Chenyingzi Li \\ Beijing New Talent Academy, China \\ 3024177658@qq.com
}

\begin{abstract}
This paper views the cultural globalization from the perspective of post-colonialism, and mainly introduces two views of cultural homogeneity and cultural heterogeneity in the context of globalization. On this basis, it interprets and criticizes the above two viewpoints from the perspective of post-colonialism, pointing out that the phenomenon of cultural globalization is a complicated process and should be treated and studied cautiously in the course of history.
\end{abstract}

Keywords: Post-colonialism, Cultural globalization, Center - edge.

\section{Introduction}

Globalization and post-colonialism are probably the two most popular and important terms in the field of social and cultural studies, and the close connection between the two is obvious. From the history of emergence and development, the colonial history of western countries, as a key link in the history of globalization, is also the root of the emergence and development of post-colonialism. Although the independence of colonial countries represents the end of colonial history, the hegemonic power from western imperialism still exists. The circulation of goods and people between different regions is proceeding at an unprecedented speed and frequency, forming many "globalized" phenomena at economic, political and cultural level. Because of this, post-colonialism pays considerable attention to the phenomenon of globalization in essence, regarding the influence of the colonial rule in the past on the colonizer culture and the derivatives of this colonial relationship and its expression and actual situation in the present. According to the post-colonialism critic Arif Dirlik, the importance of globalization for post-colonial studies first lies in its complete representation of global power relation structure, and the power relation is rooted in the heritage of western imperialism in the twentieth century. Secondly, the way local societies respond to the "pressure" of globalization is in many ways very similar to the way colonized societies respond to the rule of imperialism. This argument has been accepted by other scholars and has become the basic perspective of postcolonialism in the study of globalization.

\section{Cultural Globalization and Its Views}

Globalization is at the center of modern culture and cultural practice is at the center of globalization. The complementary logical relationship between culture and globalization is demonstrated by Tomlinson in an entire book. The "central" position here is not to put political and economic globalization on the "edge". It is to say that in the era of globalization we are all experiencing, the various complex phenomena brought by it can only be properly understood from the perspective of cultural practice. Examples of cultural globalization are readily available: McDonald's is global, Hollywood films are popular in India, and Confucius schools are set up in many countries. Simple examples actually have deep meanings. As the world becomes increasingly interconnected, cultural elements have crossed the geographical boundaries of various countries and spread to all corners of the world through advanced technologies such as high-speed transportation and all-pervasive media technologies. The frequency and speed of cultural communication and transmission have never been higher and faster, and the relationship between different cultures has become complicated and unpredictable. The views people hold about cultural globalization can be summed up in two essential points:

The first is the view of cultural homogeneity in the context of globalization. Roughly speaking, it's a globalized or westernized or Americanized view. This is reflected in the cultural level of the "American face" of cultural globalization. Those who hold this view worry that American culture, 
which represents the strong imperialism culture, will dominate the world, and that the rest culture of the world will eventually come under its power. The original diverse culture will eventually present an American look, full of American flavor. Such worry has its rationality and there are so many examples to prove it. In the process of globalization, the United States, which occupies the most advantageous position and is the first to taste the benefits of globalization, uses more and more sophisticated means to sell its culture to the world, American democratic ideas, American fast food, American brands, American movies and pop stars are everywhere around the world. This makes people worry that no matter how tenaciously their traditional culture sticks to its own style, it will eventually be irreversibly eroded by American culture. In addition, it must be noted that a lot of cultural integration and symbiosis in the process of globalization is also a kind of cultural homogenization in nature. Because of the diversity and inclusiveness of American culture itself, the idea that other "weak cultures" in the world will eventually integrate with American culture is actually a manifestation of the Americanization of local culture.

The second is the view of cultural heterogeneity opposite to the above. This view is expressed quite clearly by Thomas Friedman in the book "the world is flat". He believed that cultural competition on the globalization platform would give great potential for the development of global cultural diversity, because people have the ability to "upload", which can make local culture become part of globalization. Advanced media technologies and Internet tools offer the opportunity for people from all over the world to create or upload their own unique things. In Friedman's eyes, the picture of cultural globalization is quite beautiful. In the process of globalization, local culture can adjust its taste according to its own "interests" and take the cultural elements of globalization as the ornament of local culture. Just like the popular Italian pizza, which is essentially a piece of dough spread with various small foods and spices, Japan makes sushi pizza, Bangkok makes Thai pizza, and Lebanon makes sausage pizza. Similar examples include Google's support for 116 different languages, from Arabic to Zulu to Chinese. The diversity of culture is not threatened by globalization, and the localized culture will become one of the components of globalization. Although Mr Friedman is indeed a bit too optimistic about the prospects of globalization, the basic ideas of people who take the view of cultural heterogeneity are much the same as the above view. For example, in his book "creative destruction", Tyler Cowen argued that although globalization is destructive to traditional culture, it is creative at the same time. He encouraged people to view the reconstruction of traditional culture in the context of globalization from the perspective of creative destruction, believing that globalization has brought about cross-cultural communication, spawned a large number of satisfying modern works, and created the era of cultural prosperity we are experiencing.

Both of the above views have their merits, and it is indeed enough to analyze the various phenomena of cultural globalization in life from the perspective of taking culture as daily life practice. However, the meaning behind culture is profound and complex. Culture is a dimension of globalization, while culture itself is more than a dimension. Whether or not in the age of globalization, everyone on earth is influenced by culture. From this perspective, the analysis of the homogeneity and heterogeneity of pure culture is difficult to go deep. Focusing on the analysis of local society's response to post-colonialism from the forces of globalization (originally from the western colonial power) can provide a more profound and thorough view, and make us critically treat cultural globalization and even the concept of cultural homogeneity or heterogeneity itself.

\section{Perspective from Postcolonial Criticism}

The concern about the cultural homogenization, or the "Americanization" of traditional culture, is actually the anxiety about the western cultural hegemony. This is all too familiar to post-colonialism. Post-colonialism born of cultural criticism has always been quite alert to the communication and interaction of world culture. As an iconic figure of postcolonial theorization, Said analyzed a large number of literature works of western societies in the colonial era in the book "culture and imperialism". He linked the rise of these novels to modern capitalism and reconstructed the context of the western imperialist expansion that gave birth to modern European novels. He believed that 
western culture has a collusion with imperialism. This book, published in the early 1990s, became an important theoretical source for the concept of cultural imperialism. For the whole post-colonialism, the theorists at that time thought that it was very appropriate to use "cultural imperialism" or "neocolonialism" to explain the cultural phenomena generated by the internal relations of global society in the analysis of globalization. According to Simon Gikandi, post-colonialism, with the origin of literary criticism, has produced a series of nouns, such as hybridity and transculturation, which have been transformed or embezzled, dominating the discussion of cultural globalization. It can be said that, before the coming of the new century, the basic idea of the post-colonialism circle on cultural globalization still takes cultural imperialism as the main line, and thinks that the western cultural hegemony brought by cultural globalization will cause invasion to other cultures in the world. Essentially, the idea is established on the basis of center-edge, the pre-existing world pattern.

After the 21 st century, the attitude of post-colonialism has become more moderate and takes a more detailed view of the concepts of cultural imperialism, cultural hegemony and cultural homogeneity. With the development of The Times, the current world situation becomes more complex, and the form of imperialism is too different from the past. Although the relevant theories of imperialism are still favored by many scholars, some post-colonialism scholars think it is only because of the relatively "sophisticated" development of the theories of imperialism over the past century. Using them to analyze the interrelations between different regional societies in the context of today's globalization does not fit well. Post-colonialists suggest that, perhaps, in today's social and historical context, it would be more appropriate to view contemporary imperialism not only as a purely conscious exercise of ideology, but also as a combination of conscious ideological process and unconscious underlying structure. The implication of this view is that imperialism is no longer seen as an ideology imposed by western countries, but it will consider the attitudes and changes of nonwestern countries in dealing with imperialism. Of course, such attitudes and changes do not necessarily pander to the imperialist states, so that the course of imperialism is very similar to the way in which the global and local culture influences each other in the perspective of globalization.

Under the guidance of this ideology, post-colonialism no longer takes the center-edge pattern as an analysis model, nor does it simply study the homogenization problem brought by western cultural hegemony. Because once the center-edge pattern is broken, the "Americanized face" of culture is dialectically considered, maybe the form of music, the building mode of house and so on will have certain identity in the world. However, the cultural activity of the local society should also be included in the analysis perspective, and the response of the local society to western culture should be valued by everyone. American fast food chains in China are selling traditional Chinese food like beef rice and rice dumplings, and Indian street protests against Hollywood misrepresentations of their culture. However, the broadness of vision does not mean that the problem of cultural homogeneity does not exist. In the context of globalization, the highly critical post-colonialism still focuses on the issue of cultural homogeneity. It may be that the culture of absolute dominance no longer exists, but the invasion and annexation of neighboring cultures by culture with dominance still needs our vigilance. Post-colonialism needs to put the vision in all corners of the world to consider this problem. For example, for aboriginal cultures in southeast Asia's New Guinea and Ilian islands, cultural invasions from Indonesia are more worrying than those from the United States. Similarly, India has a more dominant culture than Sri Lanka, Vietnam is more dominant than Cambodia, and so on. When it comes to this point, Appadurai considers although the cultural forms within a small range have always been fearful of the absorption and assimilation of cultural forms with a larger range, the process of globalization has greatly accelerated the speed of absorption and assimilation, and strengthened the necessity for this to happen, especially when two cultures are geographically adjacent.

Similarly, the above situation is also an impact on cultural heterogeneity. Most of the popular books on the market today, from "the world is flat", "creative destruction" have talked about the issue of cultural globalization. Although their optimistic attitude is quite positive and their examples are mostly reasonable, they obviously ignore the invasion and annexation of the relatively weak culture by the relatively powerful culture mentioned above. In addition to the neglect of this phenomenon, the idea of cultural heterogeneity is based on media technology and the rapid transmission of global 
information. In the process of information transmission, the phenomenon of cultural hegemony always exists and cannot be ignored, and mentioned lightly like Thomas Friedman. After all, he described the case in a way that benefits his argument, and culture is far more complex and serious than the ingredients that embellish pizza. The so-called "upload" phenomenon can only be local. For the former colonies and other regions where many media technologies are not yet popular, the number of Internet users is a small proportion of the population, or the social elites are still only subject to western culture education, their culture is also in danger of being neglected and forgotten even if it is not assimilated by western culture. As with the more than 100 languages that Google supports, the goal may simply be to earn Mr Fridman's active and positive appreciation for supporting the world's cultural diversity. Even if Zulu people may be able to "upload" the culture, but that culture is likely to remain largely within their group. Because, after all, even if Zulu searches are supported, the number of people who use Google's products in English every day is probably dozens or hundreds of times greater than those who use Zulu. In the writer's opinion, even though the western culture is not absolutely dominant, it still holds the most powerful media. Therefore, as people in other parts of non-western regions, they should maintain a certain degree of vigilance and critical views on the process and consequences of cultural globalization. This concept not only looks at various cultural phenomena themselves, but also critically looks at people's comments on cultural globalization. Thinking from this perspective is also an inspiration for the criticalness of post-colonialism. No matter how imperialism and western cultural hegemony present a kind of "tolerant" attitude, postcolonialism established on the basis of resistance from people in the colonies against western colonial forces, has been committed to talking about immigration, cultural difference, resistance and the local feedback of history, philosophy and the language influenced by the context of European imperial rule.

\section{Conclusion}

In general, the phenomenon of cultural globalization is worth pondering and studying in the perspective of post-colonialism. For the two universal views of cultural globalization, cultural homogeneity and cultural heterogeneity, post-colonialism treats them critically. Because, in general, both of these views are looking from globalization to localization. Post-colonialism, which focuses on the local response to the impact of globalization, will truly spread the perspective across the world, and put forward new insights on cultural globalization from this perspective. At the same time, it should be noted that the criticalness of post-colonialism itself also provides a method, critical and dialectical thinking for viewing cultural globalization. We can't take one size to fit all. Cultural globalization is always a complex process, and its expression is brilliant. As a researcher, we should keep a calm attitude to observe and reflect critically.

\section{Acknowledgements}

Thank for the support of National Social Science Foundation of China (Item NO. 16BKS066).

\section{References}

[1]. Arif Dirlik the global in the local from the postcolonial Aura: The World Criticism in the Age of Global Capitalism Boulder, 1997.

[2]. Arjun Appdurai Disjunction and Difference from Modernity at large: Cultural Dimensions of Globalization Minneapolis: University of Minnesota Press,1996.

[3]. Bill Ashcroft \&Gareth Griffiths\& Helen Tiffin the post-colonial studies reader 2nd edition 2002.

[4]. Robert. J. C. Young Postcolonialism A very short introduction Oxford university press 2003.

[5]. John Tomlinson. Globalization and culture. Nanjing: Nanjing university press, 2002. 
[6]. Thomas Friedman, the world is flat: a brief history of the 21 st century, Hunan science and technology press, 2008-9.

[7]. Tyler Cowen, Creative destruction: globalization and cultural diversity, Shanghai people's press, 2007. 